\title{
Teachers' Resistance to Educational Change and Innovations in the Middle East and North Africa: A Case Study of Tunisian Universities
}

\section{Sihem Hamlaoui}

\section{Materials and Methods}

The research was conducted linearly and non-linearly and was comprised of several phases. The research employs a mix of quantitative and qualitative approaches: questionnaires (which include both open-ended and closed-ended questions), interviews with students, teachers, and e-learning decision-makers in the country. The first stage of the research was a thorough review of the literature. The second phase of the research design employed surveys with more specific and targeted questions and considered various variables to measure the extent to which ICT is currently applied and how students and teachers perceive teaching and learning with ICT.

\section{Populations}

A total of 250 responses were returned by the participants. The target population included students from the selected locations in Tunisia. With the aim of collecting quantitative data, all students were invited to answer the questionnaire, regardless of their field of study, age, institution, or education level. (Thus, all students who were enrolled in a bachelor's, masters, or $\mathrm{PhD}$ programme could participate.) Likewise, teachers and instructors, regardless of their discipline, status, experience level, or location, were invited to complete the survey. This study was

\footnotetext{
S. Hamlaoui $(\bowtie)$

Marburg, Germany

e-mail: hamlaous@staff.uni-marburg.de
}

(C) The Author(s) 2021

R. Ouaissa et al. (eds.), Re-Configurations, Politik und Gesellschaft des Nahen Ostens, https://doi.org/10.1007/978-3-658-31160-5_11 
conducted by using data collected from major stakeholders' teachers and students at 13 universities in Tunisia in the period from 2016 to 2018.

\section{Results and Discussion}

Problems of re-configuration and reform are not a new phenomenon. In 1513, Machiavelli wrote in The Prince "There is nothing more difficult to carry out, nor more doubtful of success, nor more dangerous to handle, than to initiate a new order of things" (cited in Nisbet 1974, p. 32). Correspondingly, Seffrin et al. (2009) define a "barrier" as "an event or condition that hinders the adoption decision" (p. 62). Based on the findings of questionnaires and interviews, some major barriers were identified regarding ICT implementation in Tunisia's higher education. In fact, the Tunisian ICT policy faces impediments ranging from personal/ individual attitudes to more general barriers related to the entire system of education and the ICT policies of universities, the Ministry of Higher Education, and the country as a whole. Studying the factors that may hinder the use of ICT in education may help teachers to overcome these impediments and become successful technology adopters in the future (Bingimlas 2009). In order to identify the impediments encountered by teachers and students when integrating ICT into the country's higher education institutions, I asked a group of faculty members (teachers, and staff) and students about the factors that may encourage a teacher to use ICT more frequently: "What would help you to use ICT more?" The collated responses are illustrated in Fig. 1.

According to the findings, most teachers have entry-level knowledge on how to use ICT (open computer, connect to internet, surf, read materials online or download them, use social media, etc.). In the following, I will consider what some studies refer to as "extrinsic barriers" (barriers that are related to organizations as opposed to individuals) and "intrinsic barriers" (those which are related to teachers, administrators, and individuals).

\section{Extrinsic Barriers}

One factor impeding the implementation of ICT in higher education begins at the university and government policy level and is related to infrastructure and funding (cost of hardware and software). This first problem, which almost all developing countries face, is the paucity of financial resources and the scarcity or 


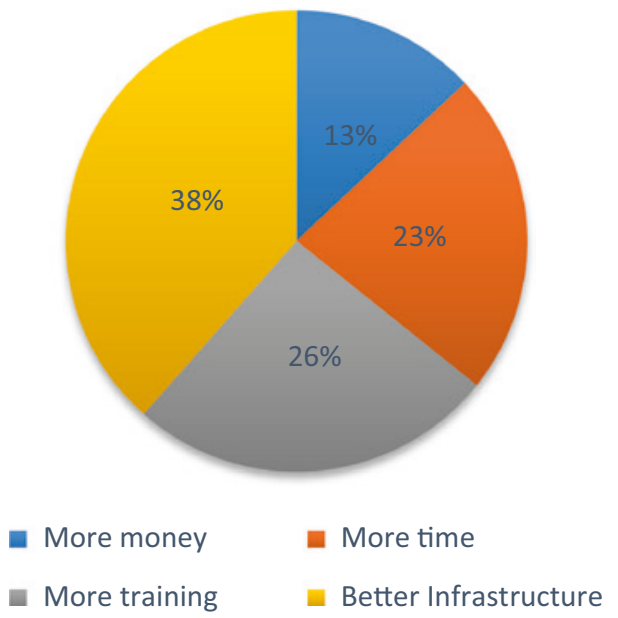

Fig. 1 What would help teachers to better use ICT?

out-datedness of equipment and resources. These factors are generally beyond the control of teachers and faculty members.

\section{The Insufficient Number of Operational Computers and Peripherals}

Many studies have pointed out that the scarcity or inadequacy of ICT infrastructure represents the main barrier to ICT adaptation. According to an ICT expert in Tunisia, infrastructural facilities such as computers, laptops, smartphones, electricity supply, and broadband connection, etc., are highly inadequate and not affordable to the middle class or people below the poverty line. Only private universities are focusing on ICT in higher education; state universities are unable to adopt it due to resource constraints (W. M. ICT expert personal online communication, 15 February 2017). Many teachers and students in the survey deemed the lack of computer rooms and the insufficient number of computers to be barriers to using ICT in teaching and learning: "It would be more convenient to have computers in class, not only in the computer room" (BA student, Sousse personal online communication, 12 February 2017). A teacher in the same institution complained:

It is impossible to always move the whole class to the computer room. First, because the students always outnumber the number of desktop computers avail- 
able, and second, we do not have enough time during the session (50 to $60 \mathrm{~min}$ ). (Teacher of English, Sousse personal online communication, 12 February 2017).

Most institutions have ICT peripherals such as keyboards or printers, which are based mainly in the computer rooms. However, teachers, students, and faculty members complained about the insufficient amount of peripheral technology relative to the large number of students and teachers. At some institutions, there is no clear policy for ICT integration. This has led to unclear goals and processes and a lack of management when it comes to plans and the usage of existing ICT resources. A dean of a university in the capital said:

I can admit that most universities have the equipment needed to start implementing technology in teaching activities, but there is clear mismanagement of resources and facilities; in each university, there should be someone responsible for the management of the whole process. (K. H. personal online communication, 12 February 2017).

There is inadequate ICT infrastructure, including computer hardware, software, and internet access, at higher education institutions. Furthermore, there is an almost total absence of ICT materials in class, apart from overhead projectors, speakers, and teachers' private computers.

\section{Lack of Trained Technical Staff}

The lack of trained teachers is another challenge hindering developing countries from adopting ICT in their education systems (Gulati 2008; Kozma 1999). Most staff and faculty members interviewed agree that there is a lack of qualified ICT personnel and skilled human resources. Most institutions lack computer-literate instructors and ICT experts to support and manage the integration of ICT in the learning and teaching process. That being said, most teachers answered "yes" to the survey question "Do you find ICT assistance in your institution when you need it?" However, when I asked this question again in a number of interviews, most teachers and faculty members admitted that "ICT assistance" is simply understood to be basic technical assistance related to fixing everyday connection problems related to the computer rooms or devices (e.g., video projectors). Even at the institutions that have settled equipment, some teachers stated that they can barely find skilled assistants to help them work with available materials.

The process of ICT integration in any teaching activity is based on the staff and faculty members' knowledge and skills. It is not easy to find skilled staff in my institution who can help. (L. L. a teacher from Nabeul, personal online communication 12 February 2017). 
In order to apply ICT in the classroom, faculty members need specialists and ICT assistants who are competent and who can fulfill the minimum requirements of teaching staff at Tunisian institutions.

\section{Lack of Adequate Training Facilities for Teachers and Instructors}

In Tunisia, the training facilities and programs for teachers and staff are still inadequate, according to the interviewees. In 2002, the Virtual University of Tunisia (VUT), a public university, was established. In collaboration with IBM, ${ }^{1}$ it offers online training programs for teachers only. One of its objectives was to offer $20 \%$ of all national courses online. This goal was never reached because there is no clearly defined strategy to encourage faculty members to adopt or use distance learning. Indeed, faculty members are very reluctant to give online courses, and the number of online courses is still limited. A VUT teacher and ICT expert said, Some institutions showed interest in our programs and courses, but still there are no clear strategies or engagement efforts. Most teachers are hesitant and reluctant. Faculty member VUT personal online communication, 12 February 2017).

\section{Large Class Sizes}

Large classes are also one of the most commonly cited barriers that hinder teachers from using educational ICT. Teachers mentioned that implementing ICT in their classes requires a small number of students to test the process and the results. There is the idea that the larger the class is, the harder the teaching process will be, especially when the teaching is based only on lectures and face-to-face communication in a class session. A larger class may result in a less interactive and collaborative session in which the teacher talks and students listen and take notes. According to the teachers I interviewed, 50\% spent the majority of the lesson time lecturing, with little time spent on practical issues, presentations by students, discussions, or group work. This does not seem to be an ideal situation for the implementation of ICT. Another teacher commented in the survey:

To start to implement ICT in my classes, I would prefer to deal with a small number of students to see how well they are able to use it and what kind of results can be achieved. I have 43 students in most of my sessions. Do you think it is easy to implement something new and evaluate the process? (L. L. a teacher from Nabeul, personal online communication, 14 February 2017).

\section{Didactic Issues}

Most teachers do not have the competencies and skills to manage and plan an ICT-based session or ICT-based materials. This is largely because they are used to a face-to-face teaching methodology that is used in lectures and is always teacher- 
and text-based. From a didactic perspective, some teachers think that ICT use distracts students and causes them to lose concentration. This leads them to say that they would never use technology because they fear they may lose control of their class. Other teachers complain that the heavy workload and limited time do not allow them to implement ICT and that they prefer to use a textbook. One faculty member said:

The system barely encourages creativity or any kind of change. Lectures are based on knowledge transmission of a large amount of information-Chap. 1 to Chap. 9-from a teacher who has been doing the same things for years. (A. L., a faculty member Gabes, personal online communication, 12 February 2017).

Another major problem is the variability in curricula at Tunisian institutions, meaning that students do not receive the same quality of education. Hence, education policy and traditional curricula have to be revised for today's needs.

Inconsistent ICT Policies and the Influence of Lobbies on Digital Strategy Planning

Tunisia has a plan for ICT integration, which includes large projects and a good strategy, "Digital Tunisia 2018." However, economic and political pressure and crises during recent years have obstructed progress due to the prioritization of issues such as fighting terrorism. The changing political landscape and changes in the Tunisian Ministry of Higher Education have affected the implementation of the policy. Another concern is that the ICT sector in Tunisia is overrun by business and politics. In 2015, the first meeting of the Strategic Council for Digital Economy (CSEN) was held, headed by the Prime Minister Habib Essid. The role of the council was to adopt and deploy new projects related to the National Strategic Plan (PNS) and "Digital Tunisia 2018." However, the council did not include representatives from civil society or ICT actors, who are meant to play a crucial role in the implementation of the National Strategic Plan for a Digital Tunisia. According to Ben Youssef, the Ministry of Communication Technologies and Digital Economy and the CSEN, which is also monitoring the National Strategic Plan and selecting experts and representatives from the private sector (2015), represent ICT actors in the public sector. ${ }^{2}$

\section{Political Factors}

Tunisia has always attempted to put education at the forefront and has allocated sufficient funds for the educational sector, with the aim of using ICT as a tool for improving education. This can be seen from the major budgetary allocations. However, since 2011, Tunisia has witnessed many political, economic, and social changes, which have had significant implications for the education sector. The 
share of the national budget spent on higher education and research decreased from $6.9 \%$ in 2010 to $4.8 \%$ in 2015 . Decision-makers and officials attributed that to the fact that the Ministry of Higher Education and Research has been integrated into the former Ministry of New Technologies and Communication, leaving both ministries with less money. Meanwhile, the combined budgets of the Tunisian Ministries of Defence and Interior increased by 15\% in 2015 (Jamel 2015, para. 3). The additional funding went to army infrastructure and the security forces. In an interview with El Fanar Media, the former Minister of Finance, Ben Hammouda, said, "We raised the defence and security sectors' budgets by 15 percent since we all agree that terrorism constitutes a major challenge to the state" (Jamel 2015, para. 8). Apart from addressing terrorism, Tunisia is also attempting to combat the violence coming from the border with its instable neighbour, Libya. According to Salem Labyedh, a former Tunisian education minister, "Limitations on the budget will hurt efforts to improve educational infrastructure. The budget for higher education will barely cover wages, much less support innovation or scientific research" (Jamel 2015, para. 12). The education sector's reprioritization stems from a lack of political will, as has been observed elsewhere: "The most notable of the barriers to the use of ICT in education in developing countries seems to be the political will of the people in the corridors of power" (Sharma 2003, p. 1).

\section{Intrinsic Barriers}

One of the first and most important—as well as common—barriers to integrating ICT into higher education is teachers' perceptions and attitude towards these technologies. Factors influencing teachers' negative attitudes towards using ICT in teaching are a lack of time, their own lack of ICT skills, and a lack of confidence in using new technology in front of a class.

\section{Teachers' Resistance to Change}

Teachers' attitudes and inherent resistance to change are a significant barrier to their ICT use in education (Cox et al. 2000; Becta 2004; Schoepp 2005). Teachers, especially those who have more experience, display a certain resistance to switching from a traditional text-based didactic method to a technology-based teaching method. I found out that some teachers are either skeptical of the effectiveness of the new methodology or do not have enough confidence in using digital resources. This is related to teachers' age and/or years of experience. I found that teachers with more teaching experience are more resistant to change; those 
who are used to the "chalk and talk" methodology are not motivated to try to integrate ICT in their teaching. An ICT expert in the MENA region said:

Adopting ICT in higher education is challenging from both pedagogical and technical points of view. Not only in developing countries, but also in other countries. Many teachers resist the adoption of ICT in their classes and many students do not know how to adapt to it. (W. M. online communication on ResearchGate).

An emotional resistance to change may not in itself be the (main) underlying reason for teachers' reluctance to use ICT in teaching, but instead can be seen as an indicator of other explanatory factors - that is, teachers may have legitimate reasons pertaining to other barriers described in this section.

\section{Length of Teaching Experience}

The longer a teacher has been teaching, the more confident and satisfied he or she tends to be with the methodology he or she has been using. Teachers with more years of experience seem more resistant to any kind of change. Whenever their university updates its policies or makes an effort towards ICT integration, that initiative is always met with slow uptake from teachers. Teachers appear to see no need to change or question their current professional methodology, resulting in their lack of acceptance of the use of ICT in their teaching. Veteran teachers are considered a real hindrance to the process of innovation in education.

\section{Lack of Competence and Digital Confidence}

Becta (2004) considers teachers' own lack of digital confidence to be a major barrier to ICT integration in classrooms. Some researchers classify it as a psychological factor, which could stem from a fear of failure, a fear of losing time, or a fear of not getting the expected results. I found that most teachers in the study are familiar only with basic ICT use, either for communication or social media or for searches on the web. Digital confidence regarding the degree to which one is able to integrate ICT into teaching is also related to more sophisticated activities that require up-to-date technical skills and competence.

\section{Lack of Motivation}

Motivation is an important positive factor, which encourages teachers to use ICT in their teaching and to move from the phase of entry and adaption to adaptation and integration. I found, however, that a group of teachers were not motivated to participate in the process. Their answers to the survey included statements such as the following: 
- "I don't like technology."

- "I am doubtful about the results."

- "I am not accustomed to ICT in the classroom."

A lack of motivation might be a reflection of the MENA region's educational paradigm, in which students and learners in general are not autonomous learners. Motivation is not a factor in itself, but a reflection of underlying issues. It stems from other factors such as digital confidence, infrastructure, time shortages, and a number of other direct and indirect barriers.

\section{Gender and ICT: A Social and Cultural Issue}

According to the latest Global Gender Gap Index (World Economic Forum 2017), Tunisia is currently ranked 117 th out of 144 countries. The gender equality in the Middle East and North Africa is at its best in Tunisia. Women work in the same fields as men with no differences in terms of position, rank, or time. However, in daily life, women in Tunisia still have more responsibilities at home and in caring for children. These domestic responsibilities are on top of their professional workloads. In this study, many working and studying women declare that men rarely help in tasks related to domestic work and childcare. There is no alternative to doing two - or three - things at the same time. Women do not have much time left to use ICT facilities, except to do easy and entertaining tasks such as using social media, chatting, and shopping. Thus, female students and teachers often do not have much time left to use ICT for developing new teaching or learning activities. This applies especially to teachers; female teachers are even more constrained than their male colleagues with respect to a lack of time and a busy work schedule, in noncoastal and particularly rural locations, where most people have no internet connection at home and go to internet cafés, which are not often or easily frequented by women for social and cultural reasons.

\section{Implementation Strategy}

\section{Diffusion of Innovation (DOI) Theory}

Faculty members in Tunisian institutions are the main drivers in the process of ICT integration; hence, they constitute the change agents. Teachers and faculty members can be classified based on Rogers's five categories of innovation adoption. ${ }^{3}$ According to Medlin (2001), the most appropriate theory for studying the adoption of technology in higher education and other educational environments is Rogers's diffusion of innovation theory (Fig. 2). 


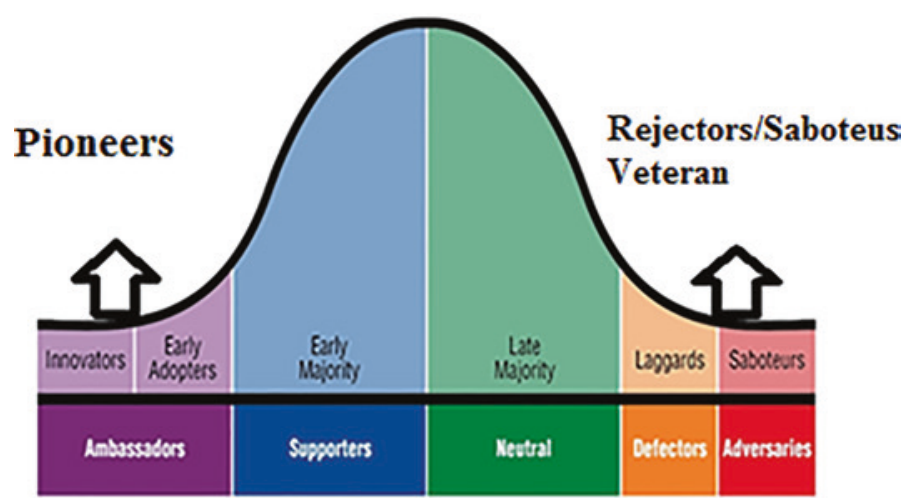

Fig. 2 Rogers's diffusion of innovation (DOI) theoryIn ICT application, the innovators are the pioneers or creators. This group of teachers does not need to be controlled or guided as they will even put their own resources towards ICT use. They have new ideas, and mostly serve as examples. These teachers are generally skilled and eager to learn; they only need better infrastructure and more resources. The second group are what Rogers calls the "early majority." They are real agents because they are a majority and they do not have many innovative ideas. However, they like to learn from new experiences and adopt to changes. These teachers need resources and much more support than the first group, as they want to be visible. A big part of the investment will go to this group through better training, better infrastructure and programs spreading awareness of innovations. Like the early majority, the late majority includes a large portion of the population; these teachers will wait until most of their peers and colleagues have adopted the innovation. These faculty members are sceptical about the process of change and its outcome. They will not join until they are persuaded that doing so is safe. This group need a lot of support, training, motivation, guidance, collaboration, and peer work. They generally have some basic knowledge of ICT, but they are ready to learn more. This readiness varies from one individual to another based on many factors, including demographic, social-psychological, and cultural factors. The last group are those whom Rogers called "laggards" (1995): the saboteurs, mostly veteran teachers, who are the most resistant to any change. They are the custodians of the traditional view of education, and they are more skeptical about reform and change agents than the late majority. The adaptation periods of all resistant teachers are relatively long, and some totally refuse to embrace the change. A major mistake is to focus on the saboteurs or the rejecters in the reform process. They should either be ignored or used as a correction factor; they may serve as bad examples of negative feedback. The process of innovation has to start with pioneers and stop before the saboteurs, as one cannot change the whole group. Good examples and success stories are needed. The focus should be on models to capture the best of what is going on and make it available. In the next section, I consider in which direction the implementation should proceed: top-down or bottom-up 


\section{Implementation Theories: Tunisia and the Case for the Top-Down Strategy}

The top-down approach is an integration technique that involves political decisions to initiate an innovation. In this approach, decision-makers are considered as the real actors in the implementation process while the administrative staff and faculty members are given little attention. In contrast to the top-down approach, the bottom-up approach recognizes the work of the actual actors and implementers. The implementers are connected with the real situation and can evaluate and review more accurately than policy-makers, who usually miss a lot of information. In the bottom-up approach, local communities are actively engaged in the development process in a participatory manner by proposing recommendations based on their individual perception of the situation (Prabhu et al. 1999). In the Tunisian case, the top-down approach produces more results and more successful ICT implementation initiatives since the system is complex. Within the bottom-up approach, only faculty members and staff would be concerned if commitment and motivation were not high, whereas adopting a top-down approach automatically guarantees the involvement of the Ministry of Technology and the Ministry of Higher Education. The top management of the Ministry of Higher Education developed the e-learning strategy and issued directives that all lecturers and course teams had to adhere to. One reason for choosing the top-down strategy is that levels of ICT adoption vary significantly from one higher education institution to another. While some institutions only have online availability of course content, others can afford to develop content management systems. Teachers are more likely to be influenced through simple communication strategies, policies, or top-down orders communicated through formal channels, instructions, email, or an intranet. The senior management should engage the staff, most of whom will reliably implement their initiatives and ideas as active agents.

\section{Conclusion}

Tunisian teachers are more likely to be influenced through simple communication strategies, policies, or orders from the top through formal channels and instructions or via emails or intranet. Senior management should engage the staff, who are mostly relied on to implement their initiatives, by acknowledging that the drivers for the e-learning process are significantly different from the institutional pressures on them (Clegg et al. 2003; Salmon 2005). This research contributes to knowledge in this field with information collected through questionnaires, interviews, and analysis of the literature, which in turn might support education 
policymakers and ICT experts in their work regarding the future development of ICT in education. Although this research has answered the proposed research questions, it may have certain limitations. Some respondents might have interpreted the questions differently from what the researcher meant and accordingly provided invalid or inaccurate responses. The number of participants could still be considered small compared to the real population of both teachers and students in higher education. Hence, uncertainty always exists concerning generalizations based on data collected through questionnaires.

\section{Endnotes}

1. For further information about IBM, see: https://www.ibm.com/planetwide/tn/.

2. For more details, see: https://bit.ly/2PSoYiH.

3. The diffusion of innovation (DOI) theory, developed by E. M. Rogers in 1962, is "one of the oldest social science theories. It originated in communication to explain how, over time, an idea or product gains momentum and diffuses (or spreads) through a specific population or social system" (Rogers 2003, p. 130).

\section{References}

Becta, A. 2004. A review of the research literature on barriers to the uptake of ICT by teachers. London: BECTA. https://publications. becta. org. uk/display. cfm.

Bingimlas, K.A. 2009. Barriers to the successful integration of ICT in teaching and learning environments: A review of the literature. Eurasia Journal of Mathematics, Science \& Technology Education 5 (3): 235-245.

Clegg, S., A. Hudson, and J. Steel. 2003. The emperor's new clothes: Globalisation and e-learning in higher education. British Journal of Sociology of Education 24 (1): 39-53.

Cox, M. J., K. Cox and C. Preston. 2000. What factors support or prevent teachers from using ICT in their classrooms? presented at the British Educational Research Association Annual Conference, University of Sussex at Brighton, September 2-5, 1999.

Gulati, S. 2008. Technology-enhanced learning in developing nations: A review. The International Review of Research in Open and Distributed Learning, 9, no. 1. https://doi. org/10.19173/irrodl.v9i1.477. Accessed: 16. June 2017.

Jamel, Ibtissem. 2015. In Tunisia, the cost of fighting terrorism is hurting higher education. Al-Fanar Media. https://www.al-fanarmedia.org/2015/06/in-tunisia-the-cost-of-terrorism-is-strangling-higher-education/. Accessed: 8 June 2020.

Kozma, R. 1999. ICT and educational reform in developing and developed countries. Centre for Technology on learning; SRI International, CA. https://rieb2-udg.es/tiec/orals/ c17.pd4. Accessed: 26 June 2017. 
Medlin, Beverly Dawn. 2001. The factors that may influence a faculty member's decision to adopt electronic technologies in instruction (Doctoral dissertation, Virginia Polytechnic Institute and State University, 2001). ProQuest Digital Dissertations. (UMI No. AAT 3095210).

Nisbet, J. 1974. Innovation-Bandwagon or Hearse? (Frank Tate Memorial Lecture, July 1974, Photocopy).

Prabhu, R., C. J. P. Colfer, and R. G. Dudley. 1999. Guidelines for developing, testing and selecting criteria and indicators for sustainable forest management: a C\&I developer's reference 1 . CIFOR.

Rogers, Everett M. 2003. Diffusion of innovations, 5th ed. New York: Free Press.

Salmon, G. 2005. Flying not flapping: A strategic framework for e-learning and pedagogical innovation in higher education institutions. ALT-J 13 (3): 201-218.

Schoepp, K. 2005. Barriers to technology integration in a technology-rich environment. Learning and Teaching in Higher Education: Gulf Perspectives 2 (1): 1-24.

Seffrin, B., P.C. Panzano, and D. Roth. 2009. What gets noticed: How barrier and facilitator perceptions relate to the adoption and implementation of innovative mental health practices. Community Mental Health Journal 45 (4): 260-269.

Sharma, R. C. 2003. Barriers in using technology for education in developing countries. Information Technology: Research and Education, 2003. Proceedings. ITRE2003. International Conference on.

World economic forum. 2017. Mind the 100 year gap. Geneva: World Economic Forum. https://www.weforum.org/reports/gender-gap-2020-report-100-years-pay-equality. Accessed: 20 June 2017.

Sihem Hamlaoui is an Arabic, English and French-speaking scholar who completed her $\mathrm{PhD}$ on the topic "ICT in higher education in the MENA region, a case study of Tunisian universities" at Philipps-Universität Marburg (Germany), where she also worked as a research assistant in the research network "Re-Configurations". She is the co-editor of the Handbook of e-learning in the Middle East and North Africa (MENA) Region, the only comprehensive resource on e-learning in the Middle East and North Africa which was published by Springer 2018. She additionally holds a B.A. in English Linguistics from the Institut Supérieur des Langues Vivantes Tunis (Tunisia). 
Open Access This chapter is licensed under the terms of the Creative Commons Attribution 4.0 International License (http://creativecommons.org/licenses/by/4.0/), which permits use, sharing, adaptation, distribution and reproduction in any medium or format, as long as you give appropriate credit to the original author(s) and the source, provide a link to the Creative Commons license and indicate if changes were made.

The images or other third party material in this chapter are included in the chapter's Creative Commons license, unless indicated otherwise in a credit line to the material. If material is not included in the chapter's Creative Commons license and your intended use is not permitted by statutory regulation or exceeds the permitted use, you will need to obtain permission directly from the copyright holder.

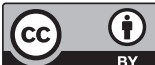

